\title{
Initiation of Vasopressor Infusions via Peripheral Versus Central Access in \\ Patients with Early Septic Shock: A Retrospective Cohort Study
}

Anthony Delaney ${ }^{1,2,3}$, Mark Finnis, ${ }^{3,4}$ Rinaldo Bellomo, ${ }^{3,5}$ Andrew Udy, ${ }^{3,6}$ Daryl Jones ${ }^{3,5}$, Gerben Keijzers ${ }^{7,8,9}$, Stephen Macdonald, ${ }^{10,11}$ Sandra Peake ${ }^{3,12}$

1. Malcolm Fisher Department of Intensive Care Medicine, Royal North Shore Hospital, Reserve Rd, St. Leonards, NSW, 2065 Australia

2. Division of Critical Care, The George Institute for Global Health, Level 5, 1 King St, Newtown, NSW, 2042, Australia

3. The Australian and New Zealand Intensive Care Research Centre, Monash University School of Public Health and Preventative Medicine, 553 St. Kilda Rd, Melbourne VIC, 3004, Australia

4. Intensive Care Unit, Royal Adelaide Hospital, Adelaide

5. Intensive Care Unit, The Austin Hospital, Melbourne

6. Department of Intensive Care and Hyperbaric Medicine, The Alfred Hospital, 55 Commercial Road, Melbourne, VIC, 3004 Australia

7. Emergency Department, Gold Coast University Hospital, Hospital Boulevard, Southport, QLD, 4215, Australia

8. Gold Coast School of Medicine, Bond University, 14 University Drive, Robina, QLD 4226, Australia

9. School of Medicine, Griffith University, Parkland Dr, Southport, QLD 4215, Australia. This is the author manuscript accepted for publication and has undergone full peer review but

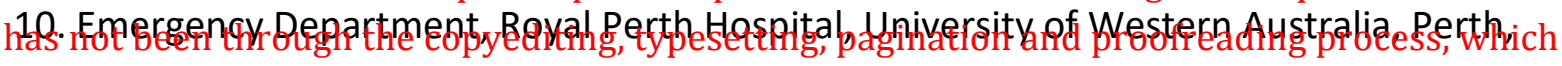
may lead to differences between this version and the Version of Record. Please cite this article as doi: 10.1111/1742-6723.13394

This article is protected by copyright. All rights reserved. 
11. Centre for Clinical Research in Emergency Medicine, Harry Perkins Institute of Medical Research, Perth, WA

12. Intensive Care Unit, The Queen Elizabeth Hospital, Adelaide

\section{Corresponding Author}

Anthony Delaney

Malcolm Fisher Department of Intensive Care Medicine

Royal North Shore Hospital

Reserve Rd, St. Leonards, NSW, 2065

Australia

Email: adelaney@georgeinstitute.org.au

Ph: $\quad+61-2-94632682$

Running Title: Peripheral versus central access for the initiation of vasopressors in patents with early septic shock

Keywords: Vasopressors, peripheral catheter, central venous catheter, septic shock, resuscitation

Word Count (manuscript): 2673

Funding sources: There were no specific funding sources for this analysis.

The ARISE trial was funded by the Australian National Health and Medical Research Council. NHMRC (grant 491075 and APP1021165)

Conflicts of interest: The authors declare that they have no conflicts of interest

Author contributions: All named authors have made substantial contributions to the conception and design of the study, or acquisition of data, or analysis and interpretation of data, the drafting of the manuscript or revising it critically for

This article is protected by copyright. All rights reserved. 
important intellectual content and all have given final approval of the version to be submitted.

This article is protected by copyright. All rights reserved. 


\section{Abstract}

Aim:

To assess whether the initiation of vasopressor infusions via peripheral venous catheters (PVC) compared to central venous catheters (CVC) in Emergency Department patients with early septic shock was associated with differences in processes of care and outcomes.

\section{Methods:}

We conducted a post-hoc analysis of the ARISE trial. We compared participants who had a vasopressor infusion first commenced via a PVC versus a CVC. The primary outcome was 90day mortality.

Results:

We studied 937 participants. Of these, 389 (42\%) had early vasopressor infusion via a PVC and 548 (58\%) via a CVC. Trial participants who received a vasopressor infusion via a PVC were more severely ill, with higher median [Interquartile range (IQR)] APACHE II scores (17 [13-23] versus 16 [12-21], $\mathrm{p}=0.003)$, and higher median [IQR] lactate $(\mathrm{mmol} / \mathrm{L})(3.6$ [1.95.8] versus 2.5 [1.5-4.5], $\mathrm{p}<0.001)$. After adjusting for baseline covariates, the estimated OR for mortality for PVC treated patients was 1.26 (95\% Cl $0.95-1.67, p=0.11)$. Trial participants who had vasopressors commenced via PVC had a shorter median (IQR) time to commencement of antimicrobials ( 55 [32-96] v 71.5 [39-119] minutes, $\mathrm{p}<0.001)$ and a shorter median (IQR) time to commencement of vasopressors (2.4 [1.3-3.9] v 4.9 [3.5-6.6] hours, $p<0.001)$.

This article is protected by copyright. All rights reserved. 


\section{Conclusion}

The practice of commencing a vasopressor infusion via a PVC was common in the ARISE trial and more frequent in trial participants with higher severity of illness. Commencement of a vasopressor infusion via a PVC was associated with some improvements in processes of care and, after adjustment, was not associated with an increased risk of death.

This article is protected by copyright. All rights reserved. 


\section{Introduction}

Sepsis is the syndrome of life-threatening organ dysfunction resulting from a dysregulated host response to infection(1). Identified as a global health priority by the World Health Organisation,(2) sepsis leads to a conservatively estimated 6 million deaths per year worldwide.(3) Patients with sepsis require early antibiotics(4) and control of the source of infection where appropriate.(5) For patients who develop septic shock,(1) the risk of mortality may be as high as $40 \%,(6,7)$. In such patients, timely haemodynamic resuscitation is crucial.(8)

Questions remain regarding the optimal approach to the haemodynamic resuscitation of patients with septic shock.(9) Observational studies suggest an association between delayed commencement of vasopressors and increased mortality in patients with sepsis, $(10,11)$ although this finding is not consistent.(12) The 2018 update of the Surviving Sepsis Campaign bundle included a strong recommendation to apply vasopressors within one hour of identification of the onset of sepsis if the patient is hypotensive during or after fluid administration.(13) This urgency to commence vasopressors can pose logistical difficulties, as vasopressor agents are traditionally delivered via a central venous catheter (CVC). Safe placement of a CVC requires expertise, time and resources that may be difficult to mobilise expeditiously. This tension has led some to advocate for the initiation of vasopressor agents via a peripheral venous catheter (PVC) rather than a CVC, $(14,15)$ although the evidence to support this practice is limited.(16)

This article is protected by copyright. All rights reserved. 
We have previously reported details of vasopressor use in the Australasian Resuscitation In Sepsis Evaluation (ARISE) trial,(17) noting that initiation of vasopressors prior to insertion of a CVC was common in this cohort.(12) Given the strong recommendations to commence vasopressors within one hour of the onset of sepsis,(13) the logistical difficulties in safely placing a CVC within this time frame, and the paucity of evidence to support the use of vasopressors via a PVC, we conducted a retrospective analysis of data from the ARISE trial to assess the association between the initiation of a vasopressor infusion via a PVC compared to a CVC in patients with early septic shock on the primary outcome of 90 day mortality, as well as secondary outcomes including key processes of care.

\section{Methods}

\section{Study design}

We conducted a post-hoc analysis using data from the ARISE trial. Details of the methods and results of the ARISE trial have been previously published. $(17,18)$ In brief, the ARISE trial was a multi-centre randomised clinical trial that compared early goal-directed therapy (EGDT) to usual care in patients with early septic shock presenting to the Emergency Department (ED). The study protocol was approved by the Human Research Ethics Committee at Monash University and at each participating institution.

\section{Participants and definition of study groups}

For this analysis we included all randomised patients who consented to continue in the trial, for whom primary outcome data were available, who received a vasopressor infusion of at least 30 minutes duration from ED presentation to 6 hours post-randomisation and had the time of insertion of a CVC recorded. We defined the exposure as initiation of vasopressors via a PVC; either when trial participants were recorded as commencing a vasopressor

This article is protected by copyright. All rights reserved. 
infusion prior to the time of insertion of a CVC or when no CVC was inserted prior to 6 hours post-randomisation. We defined the control group as those in whom the time of initiation of vasopressor infusion was subsequent to the time of insertion of a CVC, i.e. those with the first initiation of a vasopressor infusion via a CVC. We recorded baseline demographics, chronic co-morbidities,(19) group allocation (EGDT or usual care), time of day and day of the week of ED admission, seniority of the treating clinician and membership of the treating team for the first 6 hours post randomisation, and source of sepsis. For this analysis we defined baseline as those vital signs, physiological and laboratory variables closest to and before the commencement of the vasopressor infusion.

\section{Outcomes measures}

The primary outcome was all-cause mortality at 90 days post-randomisation. As the timing of vasopressor infusion may have affected fluid administration, the time to resolution of shock state, and severity of illness at ED discharge, we evaluated the following secondary outcome measures; ED length of stay, the proportion of patients who were admitted to the intensive care unit and the ICU length of stay, hospital length of stay, the requirement for, and duration of, mechanical ventilation and renal replacement therapy, mortality at 28 days, vital status at ICU and hospital discharge, adverse events related to CVC insertion and adverse events related to the administration of vasopressors via a PVC (skin necrosis and peripheral ischaemia). The effect of initiation of an infusion of vasopressors via a PVC compared to a CVC on processes of care was assessed with regards to the proportion of participants in the exposure and control groups who received a CVC, the time until CVC placement and the site of CVC placement, as well as the location within the hospital (ED v ICU). The proportion of participants receiving an arterial line and time to arterial line

This article is protected by copyright. All rights reserved. 
placement were assessed as were details of the vasopressor agents used, time to vasopressor commencement and time to commencement of norepinephrine and duration of peripheral vasopressor infusion. We assessed the association between the commencement of a vasopressor infusion via a PVC compared to a CVC on the time taken to administer intravenous (IV) antimicrobials from ED arrival, as well as on the total fluid volume from ED arrival to commencement of vasopressors, as well as through to 6 hours, 24 hours, and 72 hours post-randomisation.

\section{Statistical Analysis}

Categorical data are summarized as $\mathrm{n}(\%)$, continuous data as median [interquartile range, $[Q R]$, with between-group comparisons performed by chi-squared, t-test, or Wilcoxon ranksum test as indicated.

For the primary outcome, the unadjusted population average effect was assessed using a generalized estimating equations (GEE) model, employing a logit link and clustered by contributing site. Contributing sites with $\leq 5$ events were collapsed to a single category, leaving 17 of 51 sites. A multivariable GEE model was constructed, incorporating baseline covariates having an independent association with the primary outcome at $\mathrm{P}<0.1$. No imputation was undertaken for missing data, given such data could not be considered "missing at random", and individual covariates were considered for model inclusion only when missing data constituted $<10 \%$.

To adjust for marked covariate imbalance between groups, a propensity score model was constructed using logistic regression to estimate the probability of receiving vasopressors

This article is protected by copyright. All rights reserved. 
initially via PVC versus CVC. No imputation was undertaken for missing data and covariates with $\geq 10 \%$ missing data were omitted. Covariates were retained at $\mathrm{P}<0.1$ and, irrespective of association with treatment assignment, covariates showing a strong association with outcome were retained in the propensity score model. $(20,21)$ Covariates included in the final propensity score model included EGDT assignment, study site, age, Acute Physiology And Chronic Health Evaluation (APACHE) II score, Charlson comorbidity score groups (0, 1, 2, $\geq 3$ ), cardiac and haematology components of the SOFA (Sequential Organ Failure Assessment) score, time from ED presentation to vasopressor initiation, the interval from ED presentation to randomisation, time from ED presentation to CVC insertion and site of sepsis. The requirement for mechanical ventilation or renal replacement therapy within the first 72 hours post-randomisation were included in the propensity score model in a sensitivity analysis, given their strong association with outcome and potential influence on CVC placement or onset of vasopressor use.

Inverse probability of treatment weighting (IPW) was used to create a "pseudo-population" in which the baseline covariates were balanced, with weights stabilized and trimmed at the $1^{\text {st }}$ and $99^{\text {th }}$ centiles. (22) Propensity score model performance was assessed by covariate standardized differences $<10 \%$ between groups and propensity score overlap. The IPW pseudo-population was used to estimate the average treatment effect (ATE) of PVC-CVC group assignment via a logistic regression model with robust standard errors, and additionally via a Cox proportional hazards model for time to death, censored at day 90 . Acknowledging the probablity of significant unmeasured confounding variables, the E-value for the group ATE was calculated.(23) All analyses were undertaken in Stata MP/15.1. 


\section{Results}

The details of the derivation of the study cohort are shown in Figure 1.

\section{Baseline characteristics and processes of care according to mode of venous access}

The baseline characteristics of the two groups are shown in Table 1. ARISE trial participants who had a vasopressor infusion initiated via a PVC compared to a CVC were more severely ill as evidenced by higher APACHE II scores, lower systolic blood pressure, higher respiratory rates, higher lactate levels, lower $\mathrm{pH}$ and higher serum creatinine at baseline compared to those who had a vasopressor infusion commenced via a CVC. The associations between the initiation of a vasopressor infusion via PVC compared to CVC on processes of care are shown in Table 2. Overall, 29/389 (7.5\%) of those who had a vasopressor infusion initiated via a PVC did not receive a CVC. Compared to trial participants who had a vasopressor infusion initiated via a CVC, those who had a vasopressor infusion initiated via a PVC had a shorter time to initiation of vasopressors, a shorter time to initiation of antimicrobial therapy, a shorter duration of stay in the ED, were more likely to receive metaraminol as their initial vasopressor infusion, and received more invasive mechanical ventilation and renal replacement therapy.

\section{$\underline{\text { Association between mode of venous access and patient outcomes }}$}

The unadjusted mortality rates and adverse event rates are shown in Table 3. In the unadjusted analysis, the initiation of vasopressors via a PVC compared to a CVC was associated with an increase in the estimated odds of mortality. After adjustment for baseline co-variates, there was no significant increase in the odds of mortality, with an 
estimated OR $1.26(95 \% \mathrm{Cl} 0.94$ to $1.67, \mathrm{p}=0.11)$. This result was robust to the statistical method of adjustment as shown in Table 4. Sensitivity analysis, conducted with the requirement for mechanical ventilation and requirement for renal replacement therapy in a propensity score model produced an estimated OR of 1.22 (95\% $\mathrm{Cl} 0.85$ to $1,76, \mathrm{p}=0.29$ ). The unadjusted and adjusted survival distributions are shown in Supplementary Figure 2.

\section{Discussion}

\section{Key Findings}

We conducted a cohort study using data from the ARISE trial to assess the association between the initiation of vasopressor infusions via a PVC compared to commencing vasopressor infusions after placement of a CVC in patients with septic shock. We found that the initiation of vasopressors via a PVC was common. Participants with vasopressor infusion commenced via a PVC were more severely ill compared to those who had a vasopressor infusion commenced via a CVC. The initiation of vasopressors via a PVC was not associated with an increased risk of death after adjusting for differences in baseline covariates. Initiation via a PVC was associated with a shorter time to commencement of vasopressor, a shorter time to administration of the first dose of antimicrobials and a shorter duration of ED stay. Metaraminol was more commonly used as the initial vasopressor in those who had initial commencement of a vasopressor via a PVC. A proportion of trial participants who had vasopressors commenced via a PVC avoided placement of a CVC.

\section{Relationship to previous studies}

There are few studies assessing the safety of peripheral infusions of vasopressors. The safety of administration of vasopressors via a PVC was reported in 783 episodes of

This article is protected by copyright. All rights reserved. 
vasopressor use in 734 patients in a single ICU.(14) In the majority of episodes of vasopressor (506/783) administration, norepinephrine was the vasopressor of choice and the mean duration of therapy was 49 hours. There were 19 episodes of extravasation, none of which resulted in tissue necrosis.(14) In another single centre ED cohort study 55 patients, of whom 46 had a diagnosis of septic shock, received vasopressors via PVC.(15) Norepinephrine was used in 50 of 55 cases, with local extravasation in 2 patients and one patient developing thrombophlebitis. Another retrospective observational study used data from 202 patients, admitted to the ICU of an academic teaching hospital, who received vasopressor infusion via a PVC.(24) In this cohort, with $73 \%$ of patients diagnosed with septic shock, the majority (72\%) received norepinephrine and extravasation events occurred in $4 \%$ of patients. A systematic review assessing the reports of complications arising from the use of vasopressors via a PVC found 325 reported incidents of local tissue injury, the vast majority were case reports, and thus no conclusions regarding the relative incidence or safety regarding the practice of administering vasopressors via a PVC compared to administration via a CVC could be drawn.

In a single centre randomised clinical trial, 266 ICU patients who required therapy that was judged to be able to be delivered via either route, were randomised to commence therapy via a CVC or a PVC.(25) In this study approximately $70 \%$ of the patients were included due to a need for vasopressor therapy, the overall number of major complications was higher in the group randomised to receive therapy via a PVC initially compared to those who were randomised to initially receive a PVC (133 compared to $87, p=0.02)$. It is notable that $56 / 133$ major complications in the PVC group were related to difficulties with PVC insertion. 


\section{Strengths and limitations}

There are a number of strengths to this study. This is the largest multicentre cohort of septic shock patients in whom vasopressor infusions were initiated via a PVC, and the first to include a control group of patients who had vasopressors commenced via a CVC. The data are derived from a high-quality clinical trial with data monitoring procedures to ensure accuracy. There were 51 centres from 5 countries that contributed to the ARISE study, including large university-affiliated teaching hospitals and smaller urban and regional hospitals, thus ensuring external validity.

A major limitation relates to missing data. While multiple imputation methods could be employed, the likelihood that these data are 'missing at random' is small and the decision was therefore made to restrict variables for inclusion to those where the proportion of missing data was $<10 \%$. To lessen the impact of this limitation, (1) analyses were performed using multiple different methods, (2) sensitivity analyses were performed including all candidate variables for both multivariable prediction and propensity score models and while study size was dramatically reduced, overall inference was unchanged. Moreover, the E-value for the point estimate has been calculated and reported, allowing the reader to gain some appreciation of the strength of association unmeasured covariates would require with both the outcome and group selection to negate the observed effect. Despite these measures, given the nature of the study, inference must be circumspect. Trial participants who had vasopressors commenced via a PVC were more severely ill than those in whom the initiation of vasopressors could be delayed pending the insertion of a CVC. Despite the use of multivariate statistical methods to adjust for severity of illness, residual confounding $(26,27)$ may still be affecting the observed relationship between initiation of 
vasopressors via a PVC and mortality. It is also possible that adverse events specifically related to the use of vasopressors delivered via a PVC were underreported. The number of secondary outcomes assessed mandates a very cautious interpretation of the observed associations.

\section{Implications of study findings}

The finding that there are potential improvements in processes of care, such as reduced time to commence vasopressors associated with the initiation of vasopressors via a PVC is of considerable significance, given the Surviving Sepsis Campaign recommendation to apply vasopressors within one hour of identification of the onset of sepsis if the patient is hypotensive during or after fluid administration.(13) The early administration of antimicrobials is another key aspect of the early management of patients with $\operatorname{sepsis}(4,28)$. That antimicrobials were commenced in a relatively shorter time frame in the group of more severely ill patients, may be due to earlier recognition of the need for antibiotics in this group of patients, but also suggests the possibility of benefits from a strategy of commencing vasopressors via a PVC rather than diverting resources in the early phase of resuscitation to placement of a CVC.(29) The finding of no increased risk of mortality and some improvements in the processes of care provides some initial support for the safety of this strategy, a strategy that still requires adequately powered, methodologically sound randomised clinical trials to ascertain the relative risks and benefits.

\section{Conclusions}

The initiation of vasopressors via a PVC was common practice in patients with septic shock enrolled in the ARISE trial. This practice was associated with a reduced time to

This article is protected by copyright. All rights reserved. 
commencement of vasopressors, reduced time to antibiotics and was not associated with an increased risk of mortality. Further prospective trials are required to ascertain the safety of routinely commencing vasopressors via a PVC in patients with early septic shock.

\section{Acknowledgements}

The authors would like to thank all the ARISE trial participants, their families and carers. We are grateful to all the staff in the EDs and ICUs who made valuable contributions to the care of the ARISE trial participants.

This article is protected by copyright. All rights reserved. 


\section{References}

1. Singer M, Deutschman CS, Seymour CW, Shankar-Hari M, Annane D, Bauer M, et al. The Third International Consensus Definitions for Sepsis and Septic Shock (Sepsis-3). JAMA. 2016 Feb 23;315(8):801-10. PubMed PMID: 26903338. PMCID: PMC4968574. Epub 2016/02/24. eng.

2. Reinhart K, Daniels R, Kissoon N, Machado FR, Schachter RD, Finfer S. Recognizing Sepsis as a Global Health Priority - A WHO Resolution. N Engl J Med. 2017 Aug 3;377(5):4147. PubMed PMID: 28658587. Epub 2017/06/29. eng.

3. Fleischmann C, Scherag A, Adhikari NK, Hartog CS, Tsaganos T, Schlattmann P, et al. Assessment of Global Incidence and Mortality of Hospital-treated Sepsis. Current Estimates and Limitations. American journal of respiratory and critical care medicine. 2016 Feb 1;193(3):259-72. PubMed PMID: 26414292. Epub 2015/09/29. eng.

4. Kumar A, Roberts D, Wood KE, Light B, Parrillo JE, Sharma S, et al. Duration of hypotension before initiation of effective antimicrobial therapy is the critical determinant of survival in human septic shock. Crit Care Med. 2006 Jun;34(6):1589-96. PubMed PMID: 16625125. Epub 2006/04/21. eng.

5. Marshall JC, Maier RV, Jimenez M, Dellinger EP. Source control in the management of severe sepsis and septic shock: an evidence-based review. Crit Care Med. 2004 Nov;32(11 Suppl):S513-26. PubMed PMID: 15542959. Epub 2004/11/16. eng.

6. Kaukonen KM, Bailey M, Suzuki S, Pilcher D, Bellomo R. Mortality related to severe sepsis and septic shock among critically ill patients in Australia and New Zealand, 20002012. JAMA. 2014 Apr 2;311(13):1308-16. PubMed PMID: 24638143. Epub 2014/03/19. eng.

This article is protected by copyright. All rights reserved. 
7. Vail E, Gershengorn HB, Hua M, Walkey AJ, Rubenfeld G, Wunsch H. Association Between US Norepinephrine Shortage and Mortality Among Patients With Septic Shock. JAMA. 2017 Apr 11;317(14):1433-42. PubMed PMID: 28322415. Epub 2017/03/23. eng.

8. Rhodes A, Evans LE, Alhazzani W, Levy MM, Antonelli M, Ferrer R, et al. Surviving Sepsis Campaign: International Guidelines for Management of Sepsis and Septic Shock: 2016. Intensive Care Med. 2017 Mar;43(3):304-77. PubMed PMID: 28101605. Epub 2017/01/20. eng.

9. Perner A, Gordon AC, Angus DC, Lamontagne F, Machado F, Russell JA, et al. The intensive care medicine research agenda on septic shock. Intensive Care Med. 2017 Sep;43(9):1294-305. PubMed PMID: 28500455. Epub 2017/05/14. eng.

10. Bai X, Yu W, Ji W, Lin Z, Tan S, Duan K, et al. Early versus delayed administration of norepinephrine in patients with septic shock. Crit Care. 2014 Oct 3;18(5):532. PubMed PMID: 25277635. PMCID: PMC4194405. Epub 2014/10/04.

11. Beck V, Chateau D, Bryson GL, Pisipati A, Zanotti S, Parrillo JE, et al. Timing of vasopressor initiation and mortality in septic shock: a cohort study. Crit Care. 2014 May 12;18(3):R97. PubMed PMID: 24887489. PMCID: PMC4075345. Epub 2014/06/03. eng. 12. Udy AA, Finnis M, Jones D, Delaney A, Macdonald S, Bellomo R, et al. Incidence, Patient Characteristics, Mode of Drug Delivery, and Outcomes of Septic Shock Patients Treated with Vasopressors in the Arise Trial. Shock. 2018 Oct 30. PubMed PMID: 30379749. Epub 2018/11/01. eng.

13. Levy MM, Evans LE, Rhodes A. The Surviving Sepsis Campaign Bundle: 2018 update. Intensive Care Med. 2018 Jun;44(6):925-8. PubMed PMID: 29675566. Epub 2018/04/21. eng.

This article is protected by copyright. All rights reserved. 
14. Cardenas-Garcia J, Schaub KF, Belchikov YG, Narasimhan M, Koenig SJ, Mayo PH. Safety of Peripheral Intravenous Administration of Vasoactive Medication. J Hosp Med. 2015;10(9):581-5. Epub May 26.

15. Medlej K, Kazzi AA, El Hajj Chehade A, Saad Eldine M, Chami A, Bachir R, et al. Complications from Administration of Vasopressors Through Peripheral Venous Catheters: An Observational Study. The Journal of emergency medicine. 2018 Jan;54(1):47-53. PubMed PMID: 29110979. Epub 2017/11/08. eng.

16. Loubani OM, Green RS. A systematic review of extravasation and local tissue injury from administration of vasopressors through peripheral intravenous catheters and central venous catheters. Journal of critical care. 2015 Jun;30(3):653.e9-17. PubMed PMID: 25669592. Epub 2015/02/12. eng.

17. Peake SL, Delaney A, Bailey M, Bellomo R, Cameron PA, Cooper DJ, et al. Goaldirected resuscitation for patients with early septic shock. N Engl J Med. 2014 Oct 16;371(16):1496-506. PubMed PMID: 25272316. Epub 2014/10/02. eng.

18. Delaney AP, Peake SL, Bellomo R, Cameron P, Holdgate A, Howe B, et al. The Australasian Resuscitation in Sepsis Evaluation (ARISE) trial statistical analysis plan. Critical care and resuscitation : journal of the Australasian Academy of Critical Care Medicine. 2013 Sep;15(3):162-71. PubMed PMID: 23944201. Epub 2013/08/16. eng.

19. Charlson ME, Pompei P, Ales KL, MacKenzie CR. A new method of classifying prognostic comorbidity in longitudinal studies: development and validation. Journal of chronic diseases. 1987;40(5):373-83. PubMed PMID: 3558716. Epub 1987/01/01. eng. 20. Rubin DB, Thomas N. Matching using estimated propensity scores: relating theory to practice. Biometrics. 1996 Mar;52(1):249-64. PubMed PMID: 8934595. Epub 1996/03/01. eng.

This article is protected by copyright. All rights reserved. 
21. Schuster T, Lowe WK, Platt RW. Propensity score model overfitting led to inflated variance of estimated odds ratios. Journal of clinical epidemiology. 2016 Dec;80:97-106. PubMed PMID: 27498378. PMCID: PMC5756087. Epub 2016/08/09. eng.

22. Lee BK, Lessler J, Stuart EA. Weight trimming and propensity score weighting. PLoS One. 2011 Mar 31;6(3):e18174. PubMed PMID: 21483818. PMCID: PMC3069059. Epub 2011/04/13. eng.

23. VanderWeele TJ, Ding P. Sensitivity Analysis in Observational Research: Introducing the E-Value. Annals of internal medicine. 2017 Aug 15;167(4):268-74. PubMed PMID: 28693043. Epub 2017/07/12. eng.

24. Lewis T, Merchan C, Altshuler D, Papadopoulos J. Safety of the Peripheral Administration of Vasopressor Agents. Journal of intensive care medicine. 2017 Jan 1:885066616686035. PubMed PMID: 28073314. Epub 2017/01/12. eng.

25. Ricard JD, Salomon L, Boyer A, Thiery G, Meybeck A, Roy C, et al. Central or peripheral catheters for initial venous access of ICU patients: a randomized controlled trial. Crit Care Med. 2013;41(9):2108-15.

26. Bosco JL, Silliman RA, Thwin SS, Geiger AM, Buist DS, Prout MN, et al. A most stubborn bias: no adjustment method fully resolves confounding by indication in observational studies. Journal of clinical epidemiology. 2010 Jan;63(1):64-74. PubMed PMID: 19457638. PMCID: PMC2789188. Epub 2009/05/22. eng.

27. Sjoding MW, Luo K, Miller MA, Iwashyna TJ. When do confounding by indication and inadequate risk adjustment bias critical care studies? A simulation study. Crit Care. 2015 Apr 30;19:195. PubMed PMID: 25925165. PMCID: PMC4432515. Epub 2015/05/01. eng.

28. Seymour CW, Gesten F, Prescott HC, Friedrich ME, Iwashyna TJ, Phillips GS, et al. Time to Treatment and Mortality during Mandated Emergency Care for Sepsis. N Engl J

This article is protected by copyright. All rights reserved. 
Med. 2017 Jun 8;376(23):2235-44. PubMed PMID: 28528569. PMCID: PMC5538258. Epub 2017/05/23. eng.

29. Peltan ID, Brown SM, Bledsoe JR, Sorensen J, Samore MH, Allen TL, et al. ED Door-toAntibiotic Time and Long-term Mortality in Sepsis. Chest. 2019 May;155(5):938-46. PubMed PMID: 30779916. Epub 2019/02/20. eng.

This article is protected by copyright. All rights reserved. 


\section{Figure Legends}

Figure 1.

Derivation of the Study Cohort

ARISE = Australasian Resuscitation In Sepsis Study, CVC = Central Venous Catheter

\section{Supplementary Figure 2.}

Kaplan Meier curves displaying survival the probability of survival for those receiving vasopressors initially via a peripheral venous catheter compared to a central venous catheter (Panel A - unadjusted, Panel B - TSIPW adjusted).

VP via CVC = vasopressors infusion via central venous catheter VP via PVC = vasopressor infusion via peripheral venous catheter TSIPW = Trimmed standardized inverse probability of treatment weights.

This article is protected by copyright. All rights reserved. 
Table 1

Baseline characteristics of ARISE trial participants who had initiation of vasopressors via a Peripheral Venous Catheter compared to a Central Venous Catheter

\begin{tabular}{|c|c|c|c|c|}
\hline & & $\begin{array}{l}\text { iPVC } \\
\mathrm{N}=389\end{array}$ & $\begin{array}{l}i C V C \\
N=548\end{array}$ & $\begin{array}{l}\text { P- } \\
\text { Value }\end{array}$ \\
\hline \multicolumn{2}{|l|}{ Median age, [IQR] } & $65.4[52.4,75.3]$ & $65.7[53.6,76.0]$ & 0.45 \\
\hline \multicolumn{2}{|l|}{ Male gender, n (\%) } & $233(59.9)$ & $330(60.2)$ & 0.92 \\
\hline \multicolumn{2}{|l|}{ Median APACHE II, [IQR] } & $17[13,23]$ & $16[12,21]$ & 0.003 \\
\hline \multicolumn{2}{|l|}{ EGDT, n (\%) } & $189(48.6)$ & $314(57.3)$ & 0.008 \\
\hline $\begin{array}{l}\text { Median Charlson comorbidit } \\
\begin{array}{c}0 \\
1-2 \\
\geq 3\end{array}\end{array}$ & index & $\begin{array}{l}172(44.2) \\
150(38.6) \\
67(17.2)\end{array}$ & $\begin{array}{l}231(42.2) \\
236(43.1) \\
81(14.8)\end{array}$ & 0.33 \\
\hline \multicolumn{2}{|l|}{ Weight (kg), median [IQR] } & $77[65,90]$ & $75[65,85]$ & 0.03 \\
\hline $\begin{array}{l}\text { Source of sepsis, n (\%) } \\
\text { Lung } \\
\text { Genitourinary } \\
\text { Blood } \\
\text { Gastrointestinal } \\
\text { Soft tissue } \\
\text { Other } \\
\text { Unknown }\end{array}$ & & $\begin{array}{c}137(35.2) \\
70(18.0) \\
51(13.1) \\
27(6.9) \\
42(10.8) \\
31(8.0) \\
28(7.2)\end{array}$ & $\begin{array}{c}176(32.1) \\
101(18.4) \\
54(9.9) \\
52(9.5) \\
59(10.8) \\
46(8.4) \\
51(9.3)\end{array}$ & 0.41 \\
\hline \multicolumn{5}{|c|}{$\begin{array}{r}\text { Physiological variables: median [IQR } \\
\text { Obs }\end{array}$} \\
\hline SBP $(\mathrm{mmHg})$ & 933 & $90[80,105]$ & $96[86,109]$ & $<0.001$ \\
\hline $\begin{array}{l}\text { Heart rate (beats/minute) } \\
\text { Temperature }\left({ }^{\circ} \mathrm{C}\right)\end{array}$ & $\begin{array}{l}937 \\
858\end{array}$ & $\begin{array}{c}105[90,122] \\
37.4[36.5,38.5]\end{array}$ & $\begin{array}{c}105[90,119] \\
37.3[36.5,38.2]\end{array}$ & $\begin{array}{c}0.52 \\
0.084\end{array}$ \\
\hline Resp rate (breaths/minute) & 931 & $24[20,28]$ & $22[18,26]$ & $<0.001$ \\
\hline $\mathrm{SpO}_{2}$ & 879 & $98[95,100]$ & $98[96,100]$ & 0.044 \\
\hline GCS & 858 & $15[14,15]$ & $15[14,15]$ & 0.16 \\
\hline
\end{tabular}

\begin{tabular}{|ll}
\hline Laboratory values: median & [IQR] \\
& Obs N (\%) \\
& 821 \\
Lactate $(\mathrm{mmol} / \mathrm{L})$ & 637 \\
$\mathrm{pH}$ & 594 \\
$\mathrm{FiO}_{2}(\mathrm{~mm} \mathrm{Hg})$ & 629 \\
$\mathrm{PaO}_{2}(\mathrm{~mm} \mathrm{Hg})$ & 637 \\
$\mathrm{PaCO}_{2}(\mathrm{~mm} \mathrm{Hg})$ & 920 \\
Creatinine $(\mu \mathrm{mol} / \mathrm{L})$ & 923 \\
WCC $\left(\times 10^{9} / \mathrm{L}\right)$ & 836 \\
Bilirubin $(\mu \mathrm{mol} / \mathrm{L}$ &
\end{tabular}

This article is protected by copyright. All rights reserved. 


\begin{tabular}{|c|c|c|c|}
\hline $\begin{array}{c}\text { Coagulopathy, } \mathrm{n}(\%) \\
\text { Platelets }<100 \times 10^{9} / \mathrm{L} 905\end{array}$ & $75(20.0)$ & $99(19.0)$ & 0.55 \\
INR $\geq 1.5$ & $106(42.9)$ & $155(38.0)$ & 0.30 \\
APTT $>40$ & $58(26.0)$ & $89(22)$ & 0.28 \\
\hline Time of ED admission, $\mathrm{n}(\%)$ & & & \\
00:00-05:59 & $34(8.7)$ & $46(8.4)$ & \\
O6:00-11:59 & $183(47.0)$ & $232(42.3)$ & 0.44 \\
12:00-17:59 & $134(34.5)$ & $204(37.2)$ & \\
18:00-23:59 & $38(9.8)$ & $66(12.0)$ & \\
\hline Day of ED Admission, $\mathrm{n}(\%)$ & & & \\
Monday-Friday & $334(85.9)$ & $461(84.1)$ & 0.47 \\
Saturday-Sunday & $55(14.1)$ & $87(15.9)$ & \\
\hline Most Senior Clinician, $\mathrm{n}$ (\%) & & & \\
Intern & $1(0.3)$ & $1(0.2)$ & \\
Resident Medical officer & $7(1.8)$ & $3(0.6)$ & \\
Registrar & $32(8.2)$ & $58(10.6)$ & 0.21 \\
Senior Registrar & $80(20.6)$ & $124(22.6)$ & \\
Career Medical Officer & $2(0.5)$ & $7(1.3)$ & \\
Consultant & $263(67.6)$ & $353(64.4)$ & \\
Other / unknown & $4(1.0)$ & $2(0.4)$ & \\
\hline
\end{tabular}

iPVC= initiation of vasopressors via peripheral venous catheter, $\mathrm{iCVC}=$ initiation of vasopressors via central venous catheter, IQR = interquartile range, APACHE II = Acute Physiology and Chronic Health Evaluation, EGDT = Early Goal Directed Therapy, IDDM = insulin dependent diabetes mellitus, Obs = number of available observations, $\mathrm{SBP}=$ systolic blood pressure, Resp rate $=$ respiratory rate, $\mathrm{SpO} 2=$ peripheral oxygen saturation, $\mathrm{GCS}=$ Glasgow Coma Score, $\mathrm{FiO} 2=$ fraction of inspired oxygen, $\mathrm{PF}$ ratio $=\mathrm{PaO}_{2}: \mathrm{FiO}_{2}$ ratio, $\mathrm{WCC}=$ White cell count, INR = International normalised ratio, APPT = activated partial thromboplastin time, Most Senior clinician = Most senior clinician attending patient in the first 6 hours post randomisation

This article is protected by copyright. All rights reserved. 
Table 2

Processes of care and resuscitation interventions for ARISE trial participants who had initiation of a vasopressor infusion via a Peripheral Venous Catheter compared to a Central Venous Catheter.

\begin{tabular}{|c|c|c|c|}
\hline & $\begin{array}{c}\text { iPVC } \\
N=389\end{array}$ & $\begin{array}{c}\text { iCVC } \\
N=548\end{array}$ & P-Value \\
\hline $\begin{array}{l}\text { CVC Line Insertion } \\
\text { Total, } \mathrm{n}(\%) \\
\text { Type }\left(1^{\text {st }} \text { Inserted }\right) \\
\text { Standard CVC } \\
\mathrm{SvO}_{2} \mathrm{CVC} \\
\mathrm{PA} \mathrm{Catheter} \\
\text { PICC Line } \\
\text { Double lumen dialysis catheter } \\
\text { Other }\end{array}$ & $\begin{array}{c}190(52.8) \\
152(42.2) \\
4(1.1) \\
3(0.8) \\
10(2.8) \\
1(0.3) \\
4.0[2.9,5.2]\end{array}$ & $\begin{array}{c}276(50.4) \\
267(48.7) \\
1(0.2) \\
2(0.4) \\
2(0.4) \\
0 \\
3.7[2.7,5.2]\end{array}$ & $<0.001$ \\
\hline $\begin{array}{c}\text { CVC Insertion Site, } \mathrm{n}(\%) \\
\text { Internal Jugular } \\
\text { Subclavian } \\
\text { Femoral } \\
\text { Not recorded }\end{array}$ & $\begin{array}{l}245(63.0) \\
60(15.4) \\
46(11.8) \\
38(9.8)\end{array}$ & $\begin{array}{c}388(70.8) \\
81(14.8) \\
75(13.7) \\
4(0.7)\end{array}$ & $<0.001$ \\
\hline $\begin{array}{l}\text { CVC insertion location } n(\%) \\
\text { ED } \\
\text { ICU }\end{array}$ & $\begin{array}{l}166(46.1) \\
194(53.9)\end{array}$ & $\begin{array}{l}316(57.7) \\
232(42.3)\end{array}$ & 0.001 \\
\hline $\begin{array}{l}\text { Arterial Line Insertion, } \mathrm{n}(\%) \\
\text { Interval from ED presentation, (hours)* }\end{array}$ & $\begin{array}{c}378(97) \\
2.5[1.4,4.1]\end{array}$ & $\begin{array}{c}538(98) \\
3.3[2.1,5.0]\end{array}$ & $\begin{array}{r}0.31 \\
<0.001\end{array}$ \\
\hline $\begin{array}{l}\text { Median time (hours) from ED to } \\
\text { vasopressor commencement [IQR] }\end{array}$ & $2.4[1.3,4.1]$ & $4.9[3.5,6.6]$ & $<0.001$ \\
\hline $\begin{array}{l}\text { Initial vasopressor type, } \mathrm{n}(\%) \\
\text { Norepinephrine } \\
\text { Epinephrine } \\
\text { Metaraminol }\end{array}$ & $\begin{array}{l}293(75.3) \\
38(9.8) \\
58(14.9)\end{array}$ & $\begin{array}{l}538(98.2) \\
6(1.1) \\
4(0.7)\end{array}$ & $<0.001$ \\
\hline $\begin{array}{l}\text { Duration (hours) of vasopressor infusion } \\
\text { from ED admission, median [IQR] } \\
\text { Any route } \\
\text { Peripheral }\end{array}$ & $\begin{array}{c}26[8.6,51] \\
1.33[0.66,2.5]\end{array}$ & $27[13,47]$ & $\begin{array}{c}0.54 \\
-\end{array}$ \\
\hline $\begin{array}{l}\text { Median [IQR] time (hours) from ED to } \\
\text { commencement of norepinephrine }\end{array}$ & $3.0[1.7,4.7]$ & $5.0[3.6,6.6]$ & $<0.001$ \\
\hline $\begin{array}{l}\text { **Total IV Fluids, median }[\mathrm{IQR}] \mathrm{L} \\
\text { ED to commencement of vasopressors } \\
\text { ED to } \mathrm{T}=6 \mathrm{hrs} \\
\text { ED to } \mathrm{T}=24 \mathrm{hrs}\end{array}$ & $\begin{array}{l}3.0[2.0,3.7] \\
4.3[3.3,5.7] \\
6.1[4.5,8.1]\end{array}$ & $\begin{array}{c}2.5[0,4.0] \\
4.1[3.0,5.3] \\
5.8[4.4,7.4]\end{array}$ & $\begin{array}{c}0.008 \\
0.03 \\
0.07\end{array}$ \\
\hline
\end{tabular}

This article is protected by copyright. All rights reserved. 


\begin{tabular}{|c|c|c|c|}
\hline ED to $\mathrm{T}=72 \mathrm{hrs}$ & $8.8[6.2,11.7]$ & $8.1[5.9,10.9]$ & 0.07 \\
\hline $\begin{array}{l}\text { Median time to antimicrobials (minutes), } \\
{[\mathrm{IQR}]}\end{array}$ & $55[31,95]$ & $72[39.5,119]$ & $<0.001$ \\
\hline $\begin{array}{l}\text { Team Membership, } \mathrm{n}(\%) \\
\text { Total number, median [IQR] } \\
\text { Nurses, median [IQR] } \\
\text { Medical officers, median [IQR] }\end{array}$ & $\begin{array}{c}189 / 390(48.5) \\
3[2,4] \\
2[1,2] \\
2[0,2]\end{array}$ & $\begin{array}{c}314 / 546(57.5) \\
3[2,4] \\
1[1,2] \\
2[2,2]\end{array}$ & $\begin{array}{l}0.01 \\
0.21 \\
0.38 \\
0.14\end{array}$ \\
\hline ICU admission, n (\%) & $362(93.1)$ & $520(94.9)$ & 0.24 \\
\hline $\begin{array}{l}\text { Median Length of Stay (hours), [IQR] } \\
\text { Emergency Department } \\
\text { Intensive Care Unit } \\
\text { Hospital }\end{array}$ & $\begin{array}{c}4.0[2.7,5.7] \\
73[39,152] \\
220[118,433]\end{array}$ & $\begin{array}{c}4.3[3.1,6.3] \\
71[42,138] \\
231[142,458]\end{array}$ & $\begin{array}{l}0.01 \\
0.69 \\
0.22\end{array}$ \\
\hline $\begin{array}{l}\text { Mechanical Ventilation } \\
\mathrm{n}(\%) \\
\text { Duration (hours), median [IQR] }\end{array}$ & $\begin{array}{c}181(46.5) \\
70[24,167]\end{array}$ & $\begin{array}{c}202(36.9) \\
61[26,161]\end{array}$ & $\begin{array}{c}0.003 \\
0.96\end{array}$ \\
\hline $\begin{array}{l}\text { Renal Replacement Therapy } \\
\qquad \mathrm{n}(\%) \\
\text { Duration (hours), median [IQR] }\end{array}$ & $\begin{array}{c}83(21.3) \\
75[37,167]\end{array}$ & $\begin{array}{c}89(16.2) \\
69[25,160]\end{array}$ & $\begin{array}{l}0.05 \\
0.39\end{array}$ \\
\hline
\end{tabular}

iPVC $=$ initiation of vasopressors via peripheral venous catheter, $\mathrm{iCVC}=$ initiation of vasopressors via central venous catheter, $\mathrm{CVC}=$ central venous catheter, $\mathrm{SvO}_{2} \mathrm{CVC}=\mathrm{CVC}$ with capability to measure continuous central venous oxygen saturation, $\mathrm{PA}=$ Pulmonary artery, $\mathrm{PICC}=$ Peripherally inserted central catheter, $\mathrm{ED}=$ Emergency Department, IV = intravenous, IQR = interquartile range, $I C U$ = Intensive Care Unit

* Time from ED presentation to line insertion for those receiving a CVC or /arterial line ** Time from ED presentation until 6/24/72 hours post randomisation

This article is protected by copyright. All rights reserved. 
Table 3.

Unadjusted mortality and adverse event rates for participants in the ARISE trial for those who had initiation of vasopressors via a peripheral venous catheter compared to a central venous catheter.

\begin{tabular}{|l|c|c|c|}
\hline & iPVC & iCVC & P-Value \\
& $\mathrm{N}=389$ & $\mathrm{~N}=548$ & \\
\hline Mortality, $\mathrm{n}(\%)$ & & & \\
At 90 days & $113(29)$ & $103(19)$ & $<0.001$ \\
At 28 days & $98(25)$ & $85(16)$ & $<0.001$ \\
ICU discharge & $70(19)$ & $65(13)$ & 0.006 \\
Hospital discharge & $101(26)$ & $83(15)$ & $<0.001$ \\
\hline Central venous catheter related & & & \\
adverse events, $\mathrm{n}$ (\%) & & & \\
Bleeding & 0 & $3(0.5)$ & 0.27 \\
Arterial puncture & $1(0.3)$ & 0 & 0.42 \\
Pneumothorax & 0 & $1(0.2)$ & $>0.99$ \\
Venous thrombosis & 0 & $1(0.2)$ & $>0.99$ \\
Infection & 0 & $1(0.2)$ & $>0.99$ \\
\hline Other adverse events, $\mathrm{n}$ (\%) & $\mathrm{NR}$ & $\mathrm{NR}$ & \\
Peripheral skin necrosis & $\mathrm{NR}$ & $\mathrm{NR}$ & \\
Peripheral ischaemia & & & \\
\hline
\end{tabular}

iPVC = initiation of vasopressors via a peripheral venous catheter, $\mathrm{iCVC}=$ initiation of vasopressors via a central venous catheter, ICU = Intensive Care Unit, NR = nil reported

This article is protected by copyright. All rights reserved. 
Table 4.

Adjusted estimates for the effect of initiation of a vasopressor infusion via a PVC compared to a CVC on all-cause 90-day mortality, reported as odds ratio (OR) or hazard ratio (HR) with corresponding 95\% confidence interval $(\mathrm{Cl})$ and $\mathrm{P}$-value.

\begin{tabular}{|c|c|c|c|c|}
\hline Model & OR / HR & $95 \% \mathrm{Cl}$ & P-value & Obs (N) \\
\hline GEE Univariate $^{1}$ & 1.71 & 1.28 to 2.28 & $<0.001$ & 937 \\
\hline GEE Multivariable ${ }^{2}$ & 1.26 & 0.95 to 1.67 & 0.11 & 867 \\
\hline $\begin{array}{l}\text { Logistic regression, IPW Model } \\
\text { E-Value for point estimate }\end{array}$ & $\begin{array}{l}1.22 \\
1.45\end{array}$ & $\begin{array}{l}0.86 \text { to } 1.74 \\
1.00 \text { to } 1.97\end{array}$ & 0.26 & 749 \\
\hline Cox PH, Unadjusted ${ }^{5}$ & 1.49 & 1.12 to 1.97 & 0.006 & 908 \\
\hline Cox PH, TSIPW Model & 1.09 & 0.72 to 1.64 & 0.69 & 732 \\
\hline
\end{tabular}

1. Generalized estimating equations (GEE), logit link function with robust standard errors, clustered by contributing hospital site (see text). Estimate = OR.

2. Included covariates: EGDT group, age, APACHEII, Charlson group, SOFA haematology and cardiac scores, the intervals from ED presentation to randomization, ED presentation to CVC placement, and sepsis site.

3. Propensity score, inverse probability of treatment weighted (IPW) model on balanced pseudopopulation. Estimate $=$ OR.

4. E-value $=$ minimum OR a confounder would be required to have with both the outcome and group assignment to explain the observed effect estimate.

5. Cox proportional hazards regression model, with robust standard errors, clustered by contributing hospital site. Estimate $=\mathrm{HR}$

$\mathrm{PVC}=$ peripheral venous catheter, $\mathrm{CVC}=$ central venous catheter, $\mathrm{GEE}=$ Generalised estimating equation, IPW = inverse probability weighting, $\mathrm{PH}=$ proportional hazards model, $\mathrm{OR}=$ Odds ratio, $\mathrm{HR}=$ Hazards ratio, $\mathrm{APACHE} \mathrm{II}=$ Acute Physiology and Chronic Health Evaluation II score, SOFA, = sequential organ failure assessment, ARISE = Australasian Resuscitation In Sepsis Evaluation, EGDT = Early Goal Directed Therapy, TSIPW = Trimmed standardised inverse probability of treatment weighting.

This article is protected by copyright. All rights reserved. 
Figure 1. Derivation of the Study Cohort

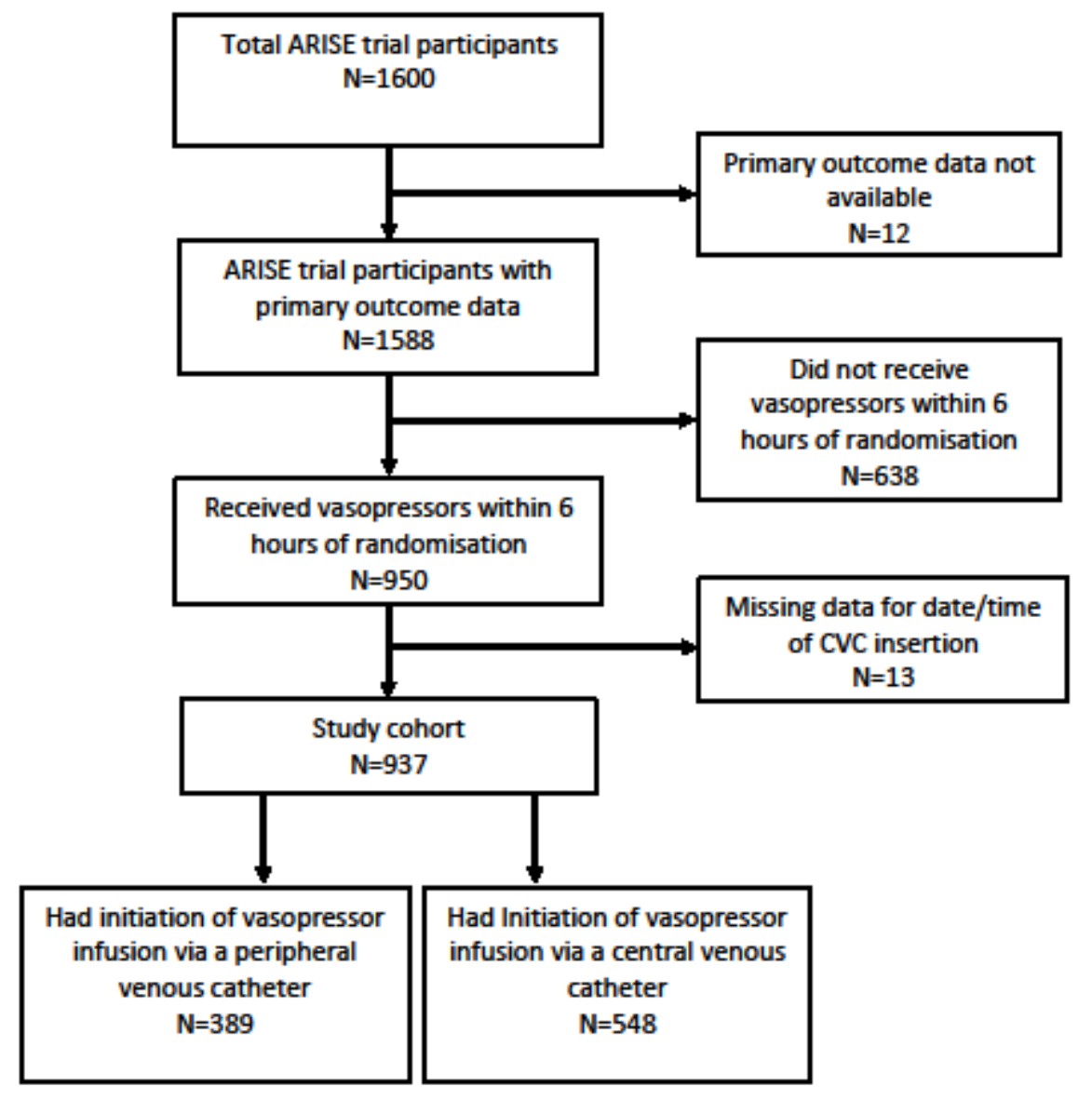

This article is protected by copyright. All rights reserved. 
Figure 2 .

Kaplan-Meier curves displaying the probability of survival for those receiving a vasopressor infusion initially via a peripheral venc compared to a central venous catheter

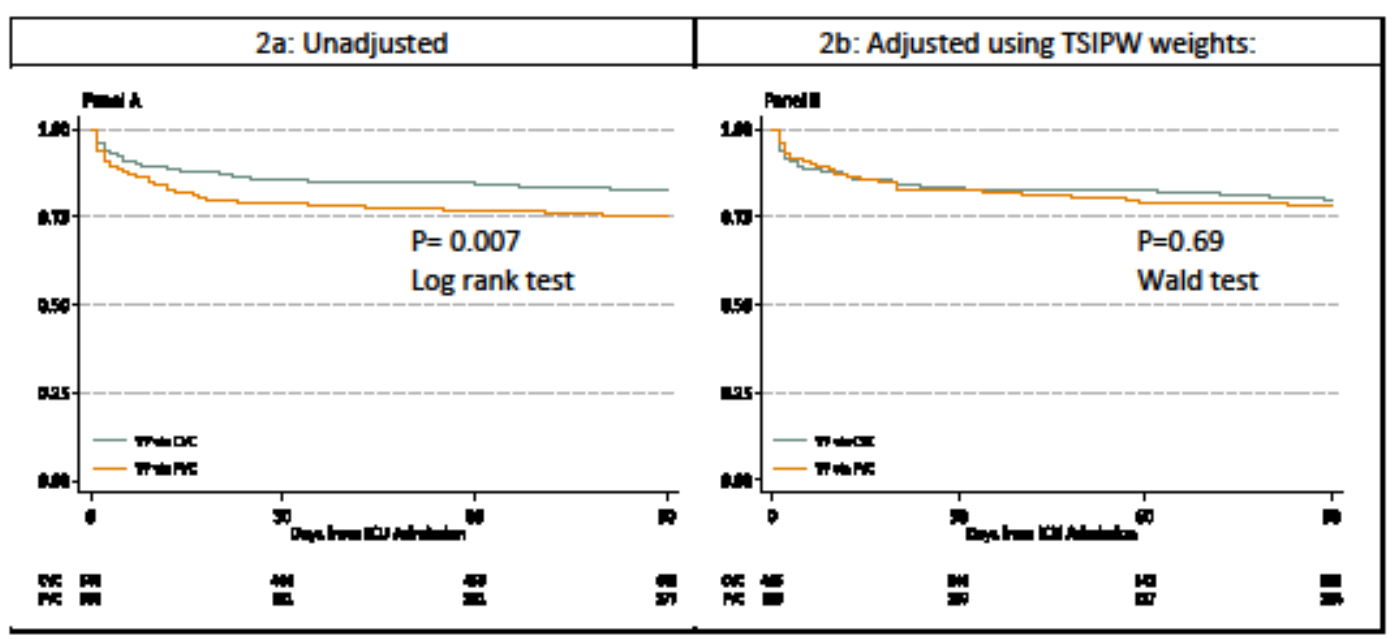

VP via CVC = initiation of vasopressors via a central venous catheter

VP via PVC = initiation of vasopressors via a peripheral venous catheter

TSIPW = Trimmed standardized inverse probability of treatment weights.

This article is protected by copyright. All rights reserved. 


\section{University Library}

\section{- M M N E R VA A gateway to Melbourne's research publications}

Minerva Access is the Institutional Repository of The University of Melbourne

Author/s:

Delaney, A;Finnis, M;Bellomo, R;Udy, A;Jones, D;Keijzers, G;Macdonald, S;Peake, S

Title:

Initiation of vasopressor infusions via peripheral versus central access in patients with early septic shock: A retrospective cohort study

Date:

2019-10-09

Citation:

Delaney, A., Finnis, M., Bellomo, R., Udy, A., Jones, D., Keijzers, G., Macdonald, S. \& Peake, S. (2019). Initiation of vasopressor infusions via peripheral versus central access in patients with early septic shock: A retrospective cohort study. EMERGENCY MEDICINE AUSTRALASIA, 32 (2), pp.210-219. https://doi.org/10.1111/1742-6723.13394.

Persistent Link:

http://hdl.handle.net/11343/286488 